\title{
PENGARUH KETEPATAN WAKTU INSEMINASI BUATAN TERHADAP TINGKAT KEBERHASILAN KEBUNTINGAN DI KECAMATAN GEDANGAN KABUPATEN MALANG JAWA TIMUR
}

\author{
Enike Dwi Kusumawati ${ }^{1}$, Syam Rahadi $^{2}$, Fendi Sudianata ${ }^{1}$, Dyah Lestari Yulianti ${ }^{1}$ \\ ${ }^{1}$ Fakultas Peternakan Universitas Kanjuruhan Malang \\ ${ }^{2}$ Fakultas Peternakan Universitas Halu Oleo Kendari \\ e-mail: enike@unikama.ac.id
}

\begin{abstract}
ABSTRAK
Penelitian ini dilaksanakan di wilayah Dinas Peternakan dan Kesehatan Hewan Kabupaten Malang-Sub Dinas Unit Pelaksana Teknis IB Kecamatan Gedangan Kabupaten Malang Provinsi Jawa Timur. Kabupaten Malang sebagai salah satu sentra peternakan rakyat sangat bergantung pada teknik Inseminasi Buatan tersebut. Dengan teknik ini sangat dimungkinkan untuk menghasilkan keturunan sapi yang memiliki daging unggul dengan harga jual yang lebih tinggi daripada sapi lokal, keadaan ini pada akhirnya akan membantu peningkatan ekonomi peternak. Selama pelaksanaan penelitian, input data berupa hari pelaksanaan IB, waktu birahi sapi betina dan waktu pelaksanaan IB. Metode yang digunakan untuk mengevaluasi pelaksanaan IB ini menggunakan metode deskriptif. Hasil penelitian evaluasi pelaksanaan IB di Kecamatan Gedangan menunjukkan bahwa IB yang dilakukan pada awal birahi memiliki tingkat keberhasilan sebesar 51,3\%, pelaksanaan IB pada rentang waktu pertengahan birahi memiliki tingkat keberhasilan $100 \%$, sedangkan pada tahap akhir birahi memiliki kemungkinan terjadinya konsepsi sebesar 30\%. Setelah dilakukan analisa dan penghitungan presentase, maka angka keberhasilan IB di Kecamatan Gedangan adalah 57,37\% dan angka ketidakberhasilan IB mencapai $42,63 \%$. Kesimpulan dari penelitian ini bahwa terdapat pengaruh ketepatan waktu IB terhadap tingkat keberhasilan kebuntingan di Kecamatan Gedangan Kabupaten Malang. Faktor-faktor penentu keberhasilan IB dalam hubungannya dengan ketepatan waktu IB adalah: kelainan anatomi saluran reproduksi, kelainan ovulasi, sel telur yang abnormal, sperma yang abnormal, dan kesalahan pengelolaan reproduksi.
\end{abstract}

Keywords: artificial insemination, conception rate, estrus, standing heat

\begin{abstract}
The study was aimed to evaluate effect of AI (Artificial Insemination) time toward the conception rate. The purpose of this study was to know the cause failure AI in cattle especially in cows. These studies show that conception rate is lower when cows are bred prior to midestrus or later than 24 hours after cessation of estrus (standing heat in this case) with 51,3\% succesfull. Conception is obtained when cows are inseminated between midestrus and the end of standing estrus, with good results up to 9 hours after estrus, with $100 \%$ succes case. These studies show that conception rate is lower when cows are bred prior to midestrus or later than 9 hours after cessation of estrus (standing heat in this case). Maximal conception is obtained when cows are inseminated between midestrus and the end of standing estrus, with good results up to 9 hours after estrus.
\end{abstract}

Keywords: artificial insemination, conception rate, estrus, standing heat 


\section{PENDAHULUAN}

Inseminasi Buatan (IB) telah menghasilkan ternak unggul hasil persilangan dengan ternak lokal maka terjadi perubahan pola pemeliharaan ternak sapi dari jenis lokal ke jenis sapi crossing (silang) sehingga IB semakin diterima peternak, sehingga peternak dalam mengawinkan sapinya mulai ada ketergantungan terhadap teknologi tersebut dengan indikasi tingginya tingkat permintaan IB (Yektiet al., 2017). Bahkan pada masa kini pasokan daging di Indonesia sangat dipengaruhi oleh keberhasilan pelaksanaan IB (Susilawati et al., 2017).

Gedangan merupakan salah satu Kecamatan di wilayah kabupaten Malang, kontribusi sektor peternakan di Kecamatan ini terhadap peternakan di kawasan Malang raya sangat besar. Dari 8 desa di Kecamatan Gedangan ada 6.076 sapi, dengan jumlah sapi betina 3.486. Dengan asumsi penggunaan teknik Inseminasi Buatan pada sapi betina maka jumlah ini akan sangat signifikan memberikan sumbangan terhadap kebutuhan pasokan daging nasional. Keberhasilan Teknik IB dipengaruhi oleh 3 faktor, yakni: (1) Peternak dan Pelaksana IB dalam mendeteksi estrus dan melakukan Inseminasi, (2) Kualitas semen sapi jantan dan (3) Kelainan hormonal, anatomi saluran reproduksi dan abnormalitas sel telur (Hafez \& Hafez, 2008).

Pelaksana IB menjadi ujung tombak keberhasilan Inseminasi, seperti yang dikemukakan oleh Kusumawati et al. (2018) bahwa keberhasilan inseminasi buatan sangat ditentukan oleh ketepatan Pelaksana IB melakukan Inseminasi, dalam hal ini tentu diperlukan konsistensi dalam menjalankan tugasnya sebagai pelaksana, berpengalaman dalam penanganan semen dan juga penempatan semen kedalam saluran reproduksi sapi betina (Ax et al., 2008; Hopkins \& Evans, 2003). Berdasarkan studi lapangan yang dilaksanakan penulis, bahwa tingkat keberhasilan pelaksanaan IB dikecamatan Gedangan pada bulan Desember 2010 sebesar 60\%. Oleh karena perlu adanya penelitian tentang pengaruh ketepatan waktu IB terhadap tingkat keberhasilan IB di Kecamatan Gedangan Kabupaten Malang.

\section{MATERI DAN METODE}

\section{Lokasi dan Waktu Kegiatan}

Penelitian ini dilaksanakan di Desa

Sindu Rejo Kecamatan Gedangan Kabupaten Malang.

\section{Materi}

Obyek umum dalam penelitian ini adalah IB sedangkan fokus utama dari kegiatan skripsi merupakan evaluasi terhadap pelaksanaan waktu IB. Sebagaimana dengan teori dasar akan pelaksanaan waktu IB dan ketercapaian target keberhasilan IB bahwa keduanya memiliki hubungan timbal balik yang akan menentukan hasil IB. Terdapat ketimpangan antara teori dengan praktek yang terjadi pada pelaksanaan IB di kecamatan Gedangan, angka keberhasilan IB pada setiap bulannya berkisar antara 60\% - 65\%. Permasalahan inilah yang menurut penulis perlu untuk dilakukan pendalaman dan evaluasi terhadap pelaksanaan waktu IB yang tepat agar nilai presentase keberhasilan IB di kecamatan Gedangan meningkat. Keluaran dari hasil evaluasi ini diharapkan mampu meningkatkan target pencapaian dan berkontribusi positif terhadap meningkatnya profesionalisme pelaksana IB dan terlebih bagi masyarakat dapat menyumbangkan efektifitas dana yang dianggarkan untuk IB.

\section{Metode}

Secara keseluruhan metode yang digunakan untuk mengevaluasi pelaksanaan IB ini menggunakan metode pengamatan langsung di lapangan yang berarti membandingkan fakta yang merupakan data yang diambil dari lapangan dengan bahan komparasi yang didapatkan dari literatur tentang pelaksanaan IB.

Pencatatan merupakan suatu kegiatan yang tidak dapat dipisahkan dari usaha peningkatan mutu ternak, karena dalam pelaksanaan IB mutlak diperlukan suatu sistem pencatatan yang rapi dan benar. 
Tanpa sistem pencatatan pelaksanaan IB tidak dapat dievaluasi dan diukur keberhasilannya. Tujuan dari pencataan adalah untuk mengetahui keadaan ternak, antara lain mengenai:

a) tanggal birahi: dengan mengetahui tanggal birahi dapat meramalkan birahi berikutnya, menentukan perkawinan yang tepat dan tanggal melahirkan;

b) tanggal pelaksanaan IB: untuk dapat melihat rentang perbedaan waktu IB terhadap keberhasilan IB;

c) tingkat produksi ternak: sehingga kita dapat memilih dan memelihara ternak yang mempunyai produksi tinggi;

d) membuat keputusan yang cermat dan tepat dalam pengelolaan ternak untuk memperoleh keuntungan maksimal.

Agar pelaksanaan pencatatan dan penarikan kesimpulan berjalan lancar, maka sistem pencatatan dan laporan harus memenuhi persyaratan: mudah dilaksanakan, berkesinambungan, di isi dengan jujur dan berisi hal-hal yang diperlukan bagi program IB. Data yang digunakan acuan adalah data pelaksanaan IB di Kecamatan Gedangan selama 32 hari kerja, setiap hari rerata pelaksanaan IB adalah 2 akseptor sehingga data yang dikumpulkan berasal dari 2 peternak. Input data seperti uraian sebelumnya berupa hari pelaksanaan IB, waktu birahi sapi betina dan waktu pelaksanaan IB. Dari ketiga data yang di catat tersebut akan diperoleh data selisih waktu antara waktu birahi sapi betina dengan waktu pelaksanaan IB.

Dari data yang sudah dikumpulkan tersebut maka akan bisa diketahui keberhasilan IB, 21 hari sejak birahi pada sapi betina. Bila sapi betina mengalami birahi kembali pada hari ke 21 sejak pelaksanaan IB berarti IB tidak berhasil dan apabila yang terjadi sebaliknya, yakni sapi betina tidak mengalami birahi maka kemungkinan besar IB berhasil.
Pada akhir pengolahan data akan diperoleh presentase keberhasilan IB di Kecamatan Gedangan, yang selanjutnya menjadi referensi tingkat keberhasilan IB selama pelaksanaan pengambilan data skripsi. Bahan komparatif yang digunakan untuk membahas analisa data menggunakan acuan buku sumber dan data yang diperoleh dari berbagai jurnal peternakan yang membahas mengenai evaluasi teknik IB.

\section{Analisis Hasil Penelitian}

Data hasil penelitian ini dianalisis secara deskriptif.

\section{HASIL DAN PEMBAHASAN}

\section{Evaluasi Keberhasilan IB}

Dari total keterlaksanaan IB selama penelitian diperoleh 35 kali IB yang berhasil, sedangkan tingkat ketidakberhasilan diperoleh 26 kali. Data yang didapatkan selanjutnya dipresentasekan untuk mengetahui tingkat keberhasilan IB di Kecamatan Gedangan.

Berdasarkan pendapat dari Ax et al. (2008) serta Hopkins \& Evans (2003) bahwa terdapat beberapa parameter untuk mengukur waktu interval masa birahi dan masa pelaksanaan IB yaitu: apabila IB dilakukan pada permulaan birahi, maka kemungkinan terjadinya konsepsi $44 \%$, sedangkan IB yang dilakukan pada pertengahan birahi perkiraan terjadinya konsepsi adalah $82 \%$, dan sebesar $75 \%$ apabila IB dilakukan pada akhir birahi. IB terkadang dapat dilakukan 6 jam sesudah birahi kemungkinan keberhasilan IB sebesar $62,5 \%, 12$ jam sesudah birahi kemungkinan terjadinya konsepsi sebesar 32,5\%, 18 jam sesudah birahi sebesar $28 \%$ dan 24 jam sesudah birahi kemungkinan terjadinya konsepsi pada sapi betina sebesar $12 \%$.

Setelah dilakukan analisa dan penghitungan presentase, maka angka keberhasilan IB di Kecamatan Gedangan adalah 57,37\% dan angka ketidakberhasilan IB pada bulan tersebut mencapai $42,63 \%$. Data yang diperoleh dikelompokkan menurut interval waktu, seperti Tabel 1. 
Tabel 1. Presentase Keberhasilan IB

\begin{tabular}{lccc}
\hline \multicolumn{1}{c}{$\begin{array}{c}\text { Interval } \\
\text { waktu } \\
\text { (jam) }\end{array}$} & $\begin{array}{c}\text { Jumlah } \\
\text { IB }\end{array}$ & $\begin{array}{c}\text { Angka } \\
\text { keberhasilan } \\
\text { IB }\end{array}$ & $\begin{array}{c}\text { Presentase } \\
\text { konsepsi } \\
(\%)\end{array}$ \\
\hline $\begin{array}{l}\text { Permulaan } \\
(1-8 \text { jam) }\end{array}$ & 39 & 20 & $51,3 \%$ \\
$\begin{array}{l}\text { Pertengaha } \\
\text { n }(9-16)\end{array}$ & 12 & 12 & $100 \%$ \\
$\begin{array}{l}\text { Akhir }(17- \\
24 \text { jam })\end{array}$ & 10 & 3 & $30 \%$ \\
\hline
\end{tabular}

Terdapat banyak faktor yang berpengaruh terhadap keberhasilan IB, antara lain pada rentang waktu birahi pada sapi betina sampai dengan waktu pelaksanaan IB. Secara garis besar Hafez\& Hafez (2008) menyebutkan bahwa IB yang dilakukan pada awal birahi memiliki perkiraan konsepsi sebesar 51,3\% hal ini tentu berbeda dengan temuan penelitian pada rentang waktu pertengahan birahi yang memiliki perkiraan keberhasilan $100 \%$. Ovulasi sel telur terjadi pada periode 15 jam setelah fase estrus. Periode pertengahan tentu memiliki persentase tertinggi dikarenakan kemungkinan terjadinya fertilisasi sangat tinggi. Sel telur yang baru diovulasikan yang masih berjalan menuju uterus, tepatnya pada cornua uteri akan segera bertemu dengan sel sperma. Setelah terjadi fertilisasi bersamaan dengan pergerakan menuju uterus akan terjadi pembelahan sel dan tepat pada dinding uterus akan terjadi konsepsi, hal ini dimungkinkan mengingat panjang cervic uteri yang mencapai $\pm 10 \mathrm{~cm}$.

Faktor-faktor penentu keberhasilan IB dalam hubungannya dengan ketepatan waktu IB adalah: kelainan anatomi saluran reproduksi, kelainan ovulasi, sel telur yang abnormal, sperma yang abnormal (Kusumawati et al., 2018), dan kesalahan pengelolaan reproduksi (Pineda, 2003). Pada tahap akhir birahi dengan durasi 17-24 jam memiliki kemungkinan terjadinya konsepsi sebesar $30 \%$, angka yang cukup besar dan dimungkinkan demikian karena sel telur yang sudah diovulasikan akan berada pada akhir cornua uteri atau pada corpus uteri dan akan menjadi tempat terjadinya fertilisasi, sel sperma dan ovum yang telah menyatu dan membentuk zigot tersebut akan mengalami konsepsi pada uterus. Selang waktu 24 jam setelah birahi sapi betina masih menunjukkan gejala estrus tapi akan menolak pejantan untuk kopulasi, cervix menutup kembali dan lendir berubah menjadi kental sebagai penyumbat, hal ini tentu berakibat tidak terjadinya konsepsi apabila dilakukan IB (Ax et al., 2008). Di kecamatan Gedangan tidak terdapat kasus dilakukannya IB pada periode 24 jam setelah birahi.

\section{KESIMPULAN}

Kesimpulan dari hasil penelitian ini yaitu terdapat pengaruh ketepatan waktu IB terhadap tingkat keberhasilan IB di Kecamatan Gedangan Kabupaten Malang. Bagi pelaksana IB sebaiknya mengupayakan pelaksaan IB pada tahap awal atau pada pertengahan estrus agar memperoleh tingkat keberhasilan IB yang tinggi.

\section{DAFTAR PUSTAKA}

Ax, R.L., M.R. Dally, B.A. Didion, R.W. Lenz, C.C. Love. D.D. Varner, B. Hafez and M.E. Bellin. 2008. Artifical Insemination. In: Reproduction In Farm Animals. E.S.E Hafez and B. Hafez. (Edit). $7^{\text {th }}$ edetion. Blackwell Publishing. Australia: 365-375.

Hafez, B. \& Hafez, E.S.E. 2008. Reproduction in Farm Animals. $7^{\text {th }}$ ed. Blackwell Publishing.

Hopkins, S.M. \& L.E. Evans. 2003. Artificial Insemination in Veterinary Endocrinology and Reproduction. Blackwell Publishing Australia Fifth Edition: 341-370.

Kusumawati, E., Betu, H., Krisnaningsih, A., \& Rahadi, S. (2018). Kualitas Semen Segar Sapi Limousin pada Lama Simpan yang Berbeda. Jurnal Ilmiah Fillia Cendekia, 3(1), 1-9. doi:10.32503/fillia.v3i1.162. 
Kusumawati, E. D., S. Rahadi, N. Isnaini, S. Wahjuningsih, A.G. Abdullah, R. Agustina, and T. Susilawati. 2018. Effect of different extender on the quality of sexing sperm before freezing in limousin cattle. IOP Conf. Ser.: Mater. Sci. Eng. 434012102.

Pineda, M.H. 2003. Veterinary Endocrinology and Reproduction. $5^{\text {th }}$ ed. Blackwell Publishing. Australia: 201-232.

Susilawati, T., E.D. Kusumawati, N. Isnaini, A.P.A. Yekti, H. Sudarwati, and A. Ridhowi. 2017. The Effect of Sexing Process by Using Density Gradient Centrifugation Percoll and Frozen Method to Sperm Motility and Membrane Damage of Ongole Crossbred Bull. In 1st International Conference in One Health (ICOH 2017). Atlantis Press.

Yekti, A.P.A., E.D. Kusumawati, Kuswati, K., A. Ridhowi, H. Sudarwati, N. Isnaini, and T. Susilawati. 2017. Succesfull of Artificial Insemination by Using Chilled Semen on Brahman Cross Cows. In 1st International Conference in One Health (ICOH 2017). Atlantis Press. 